\title{
Does income inequality affect aggregate consumption? Revisiting the evidence
}

\author{
Jesus Crespo Cuaresma ${ }^{1,2,3,4}$ - Jozef Kubala ${ }^{5}$. \\ Kristina Petrikova 5
}

Received: 31 December 2015 / Accepted: 10 April 2017 / Published online: 6 July 2017

(C) The Author(s) 2017. This article is an open access publication

\begin{abstract}
The standard Keynesian view predicts that equalization of the income distribution leads to an increase in aggregate consumption. We revisit the analysis carried out by the seminal empirical contributions which test such a hypothesis using modern econometric methods and the most comprehensive dataset existing on income distribution measures. Our results indicate that there is no empirical evidence of a negative effect of income inequality on aggregate consumption.
\end{abstract}

Keywords Inequality · Aggregate consumption · Average propensity to consume

\section{JEL Classification E22 - D31}

\section{Introduction}

The role played by inequality dynamics as a determinant of the recent economic crisis has been intensely debated in the academic literature over the last years. Rajan (2012),

\footnotetext{
The authors would like to thank an anonymous referee for comments on an earlier draft of the paper. Kristina Petrikova acknowledges financing from the Slovak Research and Development Agency under Grant APVV-15-0765: Inequality and economic growth.

$凶$ Jesus Crespo Cuaresma jcrespo@wu.ac.at

1 Vienna University of Economics and Business, Wien, Austria

2 Wittgenstein Center for Demography and Global Human Capital (IIASA,VID/OEAW,WU), Wien, Austria

3 International Institute of Applied Systems Analysis (IIASA), Laxenburg, Austria

4 Austrian Institute of Economic Research (WIFO), Wien, Austria

5 University of Economics in Bratislava, Bratislava, Slovakia
} 
notably, emphasizes that rising inequality in the USA was linked to the credit boom that eventually ended in the financial crises. Recently, the results in Bordo and Meissner (2012) challenge the conclusions in Rajan (2012) using empirical evidence for 14 countries. Similarly, Stockhammer and Wildauer (2016) find no significant effect of changes in the personal distribution of income on aggregate demand using a sample of OECD economies.

Several mechanisms linking inequality and consumption are highlighted in the literature. Effects that take place through different wealth components are analysed for example in Sousa (2010), which finds financial wealth effects to be significant and relatively large, while housing wealth effects prove not to be significant. Slacalek (2009) shows that the marginal propensity to consume from housing wealth has not only been on the rise recently but it is rather high in market-based non-euro area countries, concluding that the aggregate effect of wealth on consumption is large. In Slacalek (2006), evidence is presented concerning the fact that the marginal propensity to consume from wealth is greater for those countries with a well-functioning institutional framework.

In Frank et al. (2010), the link between the propensity to consume and inequality is explained through so-called expenditure cascades. Frank et al. (2010) provide a framework that moves away from the permanent income hypothesis and propose a context-dependent setting where the savings rate of a given income group will be affected by inequality within the group. The model predicts decreases in the savings rate with increasing inequality and links such a result empirically to the observation of decreasing saving rates and growing inequalities in the USA. Alvarez-Cuadrado and Long (2012), using also a theory based on interpersonal comparisons, find that aggregate saving decreases with income inequality.

In the post-Keynesian literature, the relationship between rising inequality and aggregate demand has been in the centre of the discussion of the causes of the financial crisis (Stockhammer 2015). The argument put forward relies on the difference in rates of consumption across households at different parts of the income distribution. To the extent that households with lower levels of income have a higher propensity to consume, increases in inequality would act as a factor that contributes to the stagnation of aggregate demand. A theoretical framework that predicts such an empirical observation has been proposed, for example by Palley (2008) in the form of a relative permanent income theory of consumption. Similar arguments are presented in Kumhof and Rancière (2010) where rising income inequality is linked to higher vulnerability to financial crisis, with the key mechanism being the transmission of a share of income earned by upper income households to low income ones, allowing them to maintain excessive consumption.

The empirical literature assessing directly the relationship between aggregate levels of consumption and the personal distribution of income at the macroeconomic level is surprisingly limited. Blinder (1975) presents empirical evidence for the USA based on an optimal life-cycle consumption model which point towards a rejection of the Keynesian postulate and indicates that increase in income inequality may result in increases in aggregate consumption. Building up in the seminal contribution by Blinder (1975), Della Valle and Oguchi (1976) exploited the variation of consumption propensities and income inequality across countries to obtain estimates of the effect of income dis- 
tribution changes on aggregate consumption. Della Valle and Oguchi (1976) conclude that, in accordance with the theoretical results in Blinder (1975), increases in income inequality may result in increased aggregate consumption. Musgrove (1980) extends the scope of data used as well as methodology applied by including more countries with better specified inputs for income and considering individual consumption functions. The analysis of the relationship between the average propensity to consume (aggregated over individual functions) and income concentration supports the view that there is no statistically significant effect of income distribution on aggregate consumption.

In this contribution, we reassess the evidence presented in Della Valle and Oguchi (1976) using data and methods that were not available when this empirical contribution was carried out. In particular, we use the most comprehensive dataset of Gini indices existing (Milanovic 2014) as well as panel data methods which are now standard but were not known in the time when the studies were carried out. In this respect, our contribution is at the same time a replication and an improvement over the empirical modelling framework provided by Blinder (1975) and Della Valle and Oguchi (1976). Our results indicate that rising inequalities are not significantly related to changes in aggregate consumption and cast serious doubts on arguments based on such a mechanism which are often found in the literature (and in particular in studies in the post-Keynesian tradition).

This note is organized as follows. Section 2 presents the empirical analysis, which relies on the modelling framework used by Della Valle and Oguchi (1976). Section 3 concludes.

\section{The empirics of consumption and income distribution}

Following the empirical implementation of Blinder (1975)'s model proposed by Della Valle and Oguchi (1976), we start by setting up panel regressions where the average propensity to consume (APC) is assumed to be affected by the average level of income per capita and the distribution of income. The APC is constructed for all available countries using data from the Penn World Table 8.1 (Feenstra et al. 2015), which is also our source for income per capita data. The Gini index based on gross household income, which is used as our measure of inequality, is sourced from Milanovic (2014). ${ }^{1}$

Figure 1 presents the scatter plot relating the APC to the Gini index for the whole available sample, which is composed by 243 country-year observations. The results of standard bivariate regressions with country fixed effects confirm that the overall positive relationship between the APC and income inequality depicted in Figure 1 is driven by the variation across countries but is not existing when just considering variability within countries. The results of such a bivariate regression are presented in the first column of Table 1.

\footnotetext{
1 The choice of the Gini index based on gross income over that computed using net income is based exclusively on data availability. We lose more than 100 country-year observations if the inequality measure based on net incomes is used. The results presented in the paper are, however, qualitatively unchanged if we use the available data on the Gini index based on net income. Detailed estimates with this alternative measure are available from the authors upon request.
} 


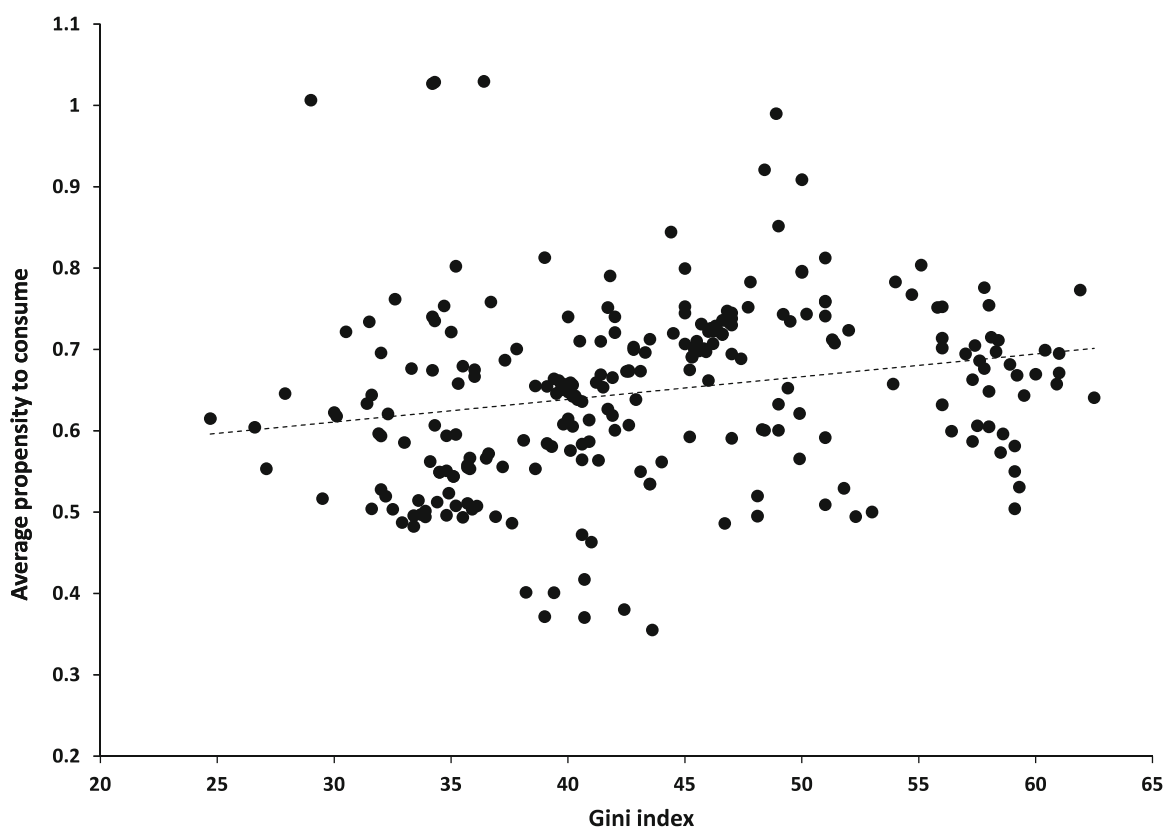

Fig. 1 Gini index versus average propensity to consume: Global sample

Table 1 Regression estimates: static specifications for the average propensity to consume

\begin{tabular}{lllll}
\hline & Bivariate & Income & Income squared & Interaction \\
\hline Gini index & -0.191 & -0.192 & -0.375 & $-0.518^{*}$ \\
& $(-0.73)$ & $(-1.11)$ & $(-2.01)$ & $(-2.09)$ \\
GDP p.c. & & $0.0125^{* * *}$ & 0.00107 & -0.00748 \\
& & $(5.22)$ & $(0.20)$ & $(-1.10)$ \\
GDP p.c. squared (/100) & & & $0.0202^{* *}$ & \\
& & & $(2.86)$ & $0.0435^{* *}$ \\
Gini index $\times$ GDP p.c. & & & & $(2.82)$ \\
& 243 & 243 & 243 & 243 \\
Observations & 0.400 & 0.574 & 0.605 & 0.603 \\
$R^{2}$ & 0.215 & 0.440 & 0.478 & 0.475 \\
Adjusted $R^{2}$ & & & &
\end{tabular}

Dependent variable is the APC, robust $t$ statistics in parentheses. Country and year fixed effects.

$* p<0.05, * * p<0.01, * * * p<0.001$

In the context of the theoretical framework set up by Blinder (1975), Della Valle and Oguchi (1976) proceed to entertain specifications which include income per capita and its square as additional regressors in the model for the APC. The estimation results for models including income as an additional regressor are presented in the second and third column of Table 1. On average, GDP per capita increases tend to 


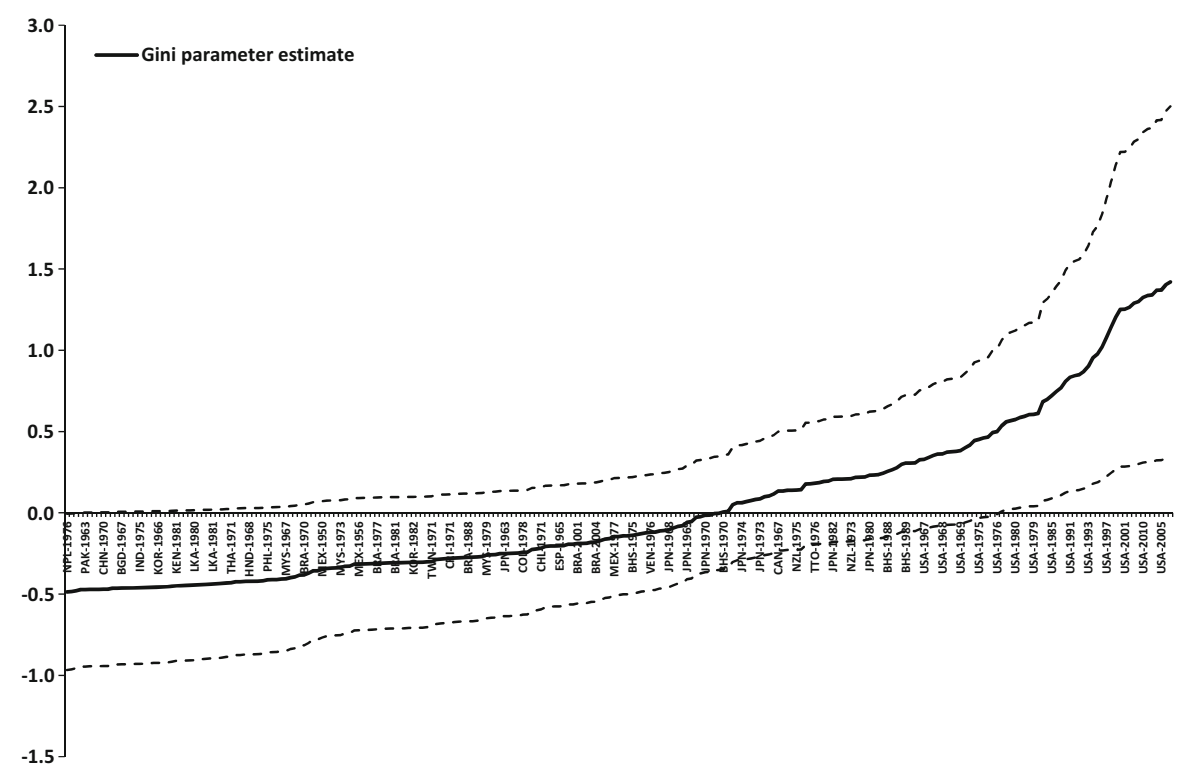

Fig. 2 Interaction effect is the static model: parameter estimates associated to different country-year observations

be related to increases in the APC, but the inclusion of this variable in the model does not affect our conclusion concerning the lack of statistical significance of the inequality variable. The results of the specification with a quadratic term of income reveal a convex relationship between the APC and GDP per capita, which is driven by the observations corresponding to the USA. If the model is reestimated without the US observations, the significance of the squared term of GDP per capita disappears, leaving the other parameter estimates qualitatively unchanged.

In order to assess heterogeneity in the potential effects of inequality on consumption by level of income, we also estimate a specification where the interaction between the Gini index and GDP per capita is included as an additional regressor (see column 4 in Table 1). The significance of the interaction term points towards a positive effect of inequality on the APC at higher levels of income per capita. Figure 2 presents the effect implied by the estimates of the model by country-year, together with a confidence interval of two standard deviations. Significant effects of inequality on the APC are again only present for the USA and indicate that, on average for the period 1985-2007, an increase in the Gini index by one percentage point tends to be related to an increase in the APC of approximately 1.1 percentage points, a result which is in contradiction to the empirical evidence in Della Valle and Oguchi (1976) and the intuition put forward by studies in the post-Keynesian tradition.

Finally, in line with the empirical specifications entertained in Della Valle and Oguchi (1976) and in the spirit of the theoretical framework put forward by Blin- 
der (1975), we expand our model to a dynamic specification. ${ }^{2}$ Table 2 presents the estimation results of specifications including a lag of the APC as an additional regressor. Such dynamic panel models need to be estimated using generalized method of moments (GMM) methods, since the usual assumption of zero correlation between the regressors and the error term is not fulfilled by construction, due to the presence of cross-sectional fixed effects. Given the persistent nature of the dependent variable in our regression model, the system-GMM estimator proposed by Blundell and Bond (1998) appears as the most adequate technique to estimate the model under consideration. The first column of Table 2 shows the estimates obtained using standard least square dummy variable methods, while the second and third column present the estimates of two different specifications (with and without interaction term) using system-GMM methods. The results in these three columns of Table 2 indicate that the insights concerning the lack of influence of changes in income inequality on the APC gained through the static specifications are robust to the inclusion of a lag of the dependent variable as an additional regressor. This is the case in spite of the fact that the APC presents strong persistence over time, as reflected in the estimates of the autoregressive parameter of the models estimated using system-GMM.

The fourth and fifth columns in Table 2 present the estimates of the dynamic model by income level. The fourth column shows the results for the sample of countries in the World Bank's "High income" (both OECD and non-OECD) category. As in the case of the static specifications, significant positive effects of inequality increases on the APC are observed in this subsample, driven by the observations corresponding to the USA. When the specification is estimated for the rest of the sample (see column five in Table 2), no significant effect of changes in the Gini index on consumption propensities is found. The same result applies if the sample is divided using financial depth as measured through private credit over GDP (sourced from the World Bank's World Development Indicators). Column 6 in Table 2 presents the results for countryyear observations above the median value of private credit over GDP for the sample at hand, and column 7 shows the estimates for those observations below the median. The results mimic those found when dividing the sample by income level and confirm the result that no significant negative effect of inequality increases on the APC is present in the data.

\section{Conclusions}

Using the most comprehensive dataset of comparable income inequality measures existing, we reassess the evidence concerning the link between aggregate consumption and income distribution changes. Our estimation results, based on a global sample and the empirical implementation put forward originally by Della Valle and Oguchi (1976), indicate that there is no significant aggregate negative effect of increases in inequality on average consumption propensities.

\footnotetext{
2 The Im-Pesaran-Shin (IPS) test for panel unit roots confirms that, in spite of its high persistence, the APC can be considered stationary for the panel at hand. The IPS test statistic for the panel of APC observations equals $-3.58(p$ value $=0.0002)$.
} 


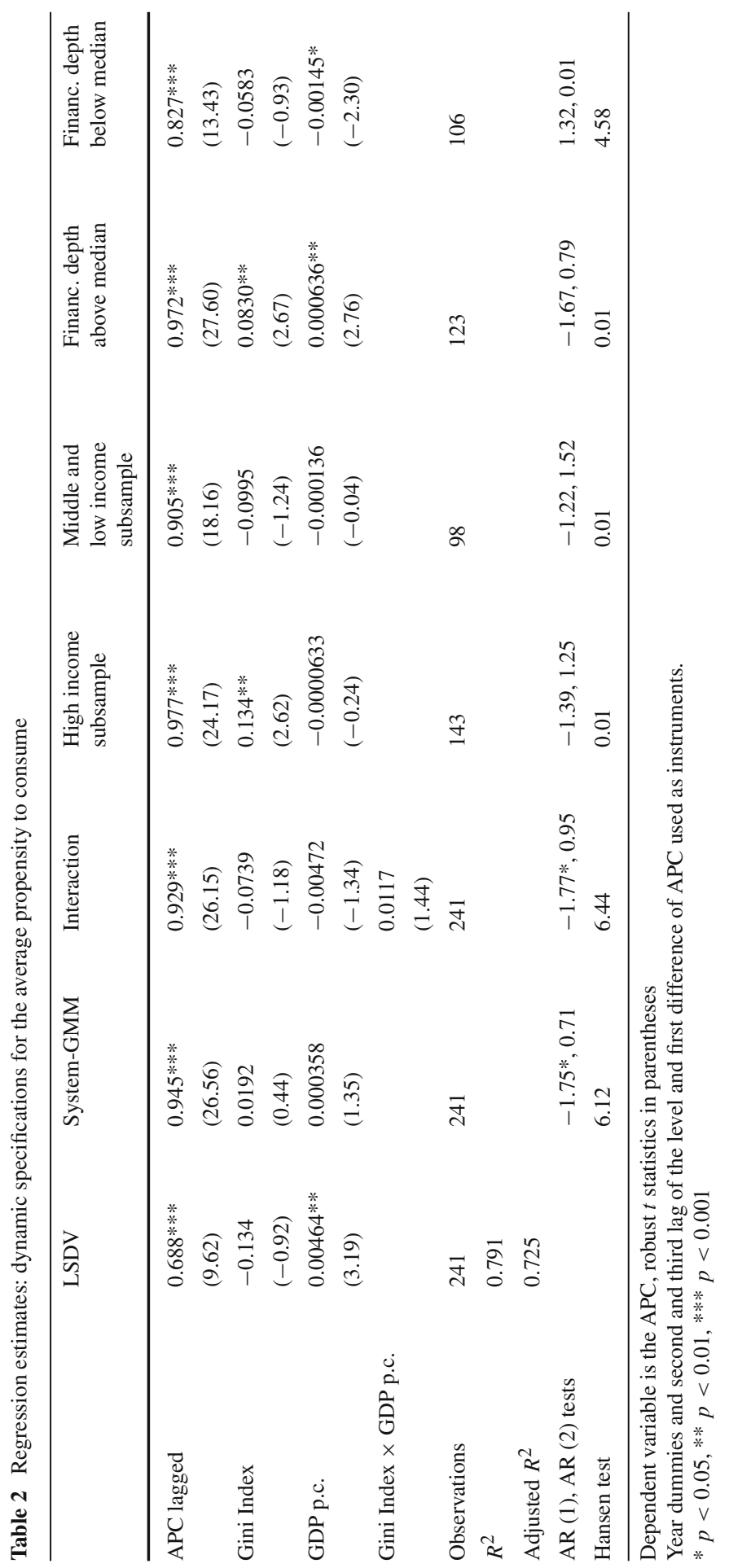


Acknowledgements Open access funding provided by Vienna University of Economics and Business (WU).

Open Access This article is distributed under the terms of the Creative Commons Attribution 4.0 International License (http://creativecommons.org/licenses/by/4.0/), which permits unrestricted use, distribution, and reproduction in any medium, provided you give appropriate credit to the original author(s) and the source, provide a link to the Creative Commons license, and indicate if changes were made.

\section{References}

Alvarez-Cuadrado F, Long NV (2012) Envy and inequality*. Scand J Econ 114(3):949-973

Blinder AS (1975) Distribution effects and the aggregate consumption function. J Political Econ 83(3):447475

Blundell R, Bond S (1998) Initial conditions and moment restrictions in dynamic panel data models. J Econom 87(1):115-143

Bordo MD, Meissner CM (2012) Does inequality lead to a financial crisis? J Int Money Financ 31(8):21472161 (Policy implications and lessons from global financial crisis)

Della Valle PA, Oguchi N (1976) Distribution, the aggregate consumption function, and the level of economic development: some cross-country results. J Political Econ 84(6):1325-1334

Feenstra RC, Inklaar R, Timmer MP (2015) The next generation of the Penn World Table. Am Econ Rev 105(10):3150-3182

Frank RH, Levine AS, Dijk O (2010) Expenditure cascades. Social Science Research Network Working Paper

Kumhof M, Rancière RG (2010) Inequality, leverage and crises. IMF working Papers

Milanovic B (2014) All the Ginis Dataset. http://econ.worldbank.org/projects/inequality. Updated November 2014

Musgrove P (1980) Income distribution and the aggregate consumption function. J Political Econ 88(3):504525

Palley TI (2008) The relative income theory of consumption: a synthetic Keynes-Duesenberry-Friedman model. PERI Working Papers

Rajan R (2012) Fault lines. HarperCollins Publishers, New York

Slacalek J (2006) International wealth effects. DIW-Diskussionspapiere, No. 596

Slacalek J (2009) What drives personal consumption? the role of housing and financial wealth. BE J Macroecon 9(1):1-37

Sousa R (2010) Wealth effects on consumption: evidence from the euro area. Banks Bank Syst 5:70-78

Stockhammer E (2015) Rising inequality as a cause of the present crisis. Camb J Econ 39(3):935-958

Stockhammer E, Wildauer R (2016) Debt-driven growth? Wealth, distribution and demand in OECD countries. Camb J Econ 40(6):1609-1634 